JOURNAL OF BIOMEDICAL RESEARCH \& CLINICAL

PRACTICE

\title{
Knowledge of Salt intake and Blood Pressure Control among Hypertensive Patients in a Tertiary Hospital
}

Adeagbo AO, Omosanya OE, ${ }^{*}$ Ayodapo AO, ${ }^{1}$ Elegbede OT, Shabi OM.

Department of Family Medicine, Federal Teaching Hospital, Ido-Ekiti.Ekiti State. Nigeria.

${ }^{I}$ Department of Family Medicine, Federal Medical Centre, Birnin-Kebbi, Kebbi State. Nigeria.

\section{ABSTRACT}

*Corresponding Author: Omosanya OE, ${ }^{1}$ Department of Family Medicine, Federal Teaching Hospital, Ido-Ekiti.Ekiti State. Nigeria.

As the prevalence of hypertension increases in adult Nigerians, achieving target blood pressure (BP) control has become an important management challenge. High salt intake is an important risk factor for hypertension and its high intake prevents adequate BP control. This study aims to explore the knowledge of salt intake and blood pressure control among hypertensive patients. Data were collected from a cross-sectional sample involving 564 adult hypertensive patients that were followed for at least 3 months prior to recruitment to this study. Data collection comprised interviewer-administered structured questionnaires about demographics, knowledge and practices related to salt, followed by measurement of blood pressure. A majority ( $92.9 \%)$ of the respondents knew that eating too much salt could affect health and less than one-half $(40.1 \%)$ actually knew that not more than one teaspoon of salt should be consumed daily. Nearly all respondents (516) knew high BP to be a possible consequence of high salt intake. Among those that took a lot of salty food, $87.7 \%$ and $78.5 \%$ had high systolic BP and diastolic BP respectively. Although the majority of respondents were knowledgeable about the adverse effects of salt, few knew the daily intake recommended value. The higher the dietary salt intake, the higher the chances of having poor BP control. Increased knowledge about recommended salt intake and individual guidance could be important for reducing salt intake in hypertensive patients.

Keywords: Blood pressure, Hypertension, Knowledge, Salt intake.

2018 Journal Impact Factor: 1.10

Print ISSN: 2636-7378 | Online ISSN: 2651-5865

\section{INTRODUCTION}

$\mathrm{G}^{\prime}$ lobally, a causal link between sodium intake and high blood pressure levels is well-established. ${ }^{1,2}$ Excess sodium intakes is associated with increased blood pressure ${ }^{3}$. Hence, salt consumption is important among patients with hypertension. Evidence suggests that modest reductions in dietary sodium could substantially reduce cardiovascular events and medical costs, and should be a public health priority. ${ }^{4}$ Internationally, calls have been made for dietary sodium reduction to be a major intervention for prevention and control of non-communicable diseases. ${ }^{5}$ The World health organization (WHO) recommends consuming sodium no more than 2 gram/day or 5 gram/day for salt intake among hypertensive patients. ${ }^{6,7}$ People with cardiovascular diseases, as well as hypertension, should reduce and limit salt consumption. ${ }^{6,8}$ It is known that low salt intake is challenging and difficult to follow. ${ }^{6,9}$ As a result, the excessive salt and sodium consumption is often unpreventable. Overconsumption of salt has positive correlation with blood pressure. Patients with hypertension will have higher systolic and diastolic blood pressure if they cannot control their daily salt consumption. ${ }^{8}$ Identification of dietary salt along with understanding the knowledge, attitude and behaviour related to salt are the first steps in reduction of salt consumption. ${ }^{10}$ As clinicians, we have always tried to use a paternalistic (parent-child) approach to counsel the patients to reduce dietary salt intake. It is usually done in a clinic setting. For this reason, the response has not 
been up to the desired extent. It requires much more than an outpatient department-based doctor-patient interaction.

Knowledge, attitude and behaviour related to salt intake are known to affect individual salt consumption. ${ }^{11}$ Increasing hypertension population's knowledge, and improving their attitude and behaviour related to salt is crucial, however, understanding on their knowledge and behaviour are the first stage of action. To date, there is limited information about knowledge; attitude and behaviour related to dietary salt among patients with hypertension in Nigeria, hence the need for this study.

\section{MATERIALS \& METHODS}

This was a descriptive cross-sectional study conducted in the Family Medicine department of the Federal Teaching Hospital, Ido-Ekiti. Ekiti State. This tertiary level healthcare facility provides medical care and serves as referral center for other health institutions in the state and environs.

The participants were hypertensive patients aged 18 years and above, and have been on treatment for at least 3 months, excluding those with co-morbidity, complications of hypertension, pregnant women, and critically ill patients.

A minimum sample size was statistically determined for the study, and 564 participants were recruited, using a hypertension prevalence rate derived in a study done in Osun State, Southwestern, Nigeria. ${ }^{12}$ with the confidence interval of $95 \%$ and standard error of 5\%. Systematic random sampling technique was used to recruit participants among the hypertensive patients attending the clinic.

Pretested semi-structured questionnaire drafted in English Language and translated in Yoruba (local language) and backtranslated into English was used to obtain relevant information on characteristics of respondents, knowledge, attitude and practices about salt intake.

Blood pressure was measured using an appropriate cuff-sized Accosson ${ }^{\circledR}$ mercury sphygmomanometer and Littman stethoscope. First appearance of sound was used for systolic, and a phase 5 Korotkoff sound (disappearance of sound) was used to measure diastolic blood pressure. Hypertensive patients were defined as persistent systolic blood pressure (SBP) $\geq 140$ $\mathrm{mmHg}$ and/or diastolic blood pressure (DBP) $\geq 90 \mathrm{mmHg}$ in consecutive measurements. ${ }^{6,11}$ Participants were classified as controlled ( SBP < $140 \mathrm{mmHg}$ and/or DBP < $90 \mathrm{mmHg}$ ) and uncontrolled hypertensive group (SBP $\geq 140 \mathrm{mmHg}$ and/or
DBP $\geq 90 \mathrm{mmHg}$ ) based on the report of the eight-joint national committee, using their evidence-based guideline for management of high blood pressure in adults. ${ }^{13}$

Data collected were entered into and analyzed with SPSS 20 software (SPSS Inc., Chicago, IL, USA). Frequency tables and diagrams in the form of charts were generated for relevant variables. Means, standard deviations (SDs), proportions, and percentages were determined as appropriate. The means and SD were calculated for continuous variables while categorical variables were summarized using proportions. Test of significance was done using Pearson's Chi-square test. $P \leq 0.05$ was taken to be statistically significant.

Ethical approval was obtained from the Institution Ethical review and Research Committee of the hospital. Informed verbal and written consent was obtained from the participants before the administration of questionnaires.

\section{RESULTS}

The socio-demographic profile of the respondents in this study showed that the mean age in years was $60.0 \pm 9.3$ years. Table 1 showed that majority $(92.9 \%)$ of respondents knew that eating too much salt could affect health, while $19.1 \%$ knew that not more than half teaspoon of salt should be consumed daily. Most of the respondents were of the opinion that majority of daily salt intake was from salt added to food (80.5\%). Half (49.5\%) of the respondents hardly ate salty food while more than two-thirds (71.6\%) of respondents hardly add extra salt to food.

Figure 1 showed that nearly all, 92.0\% (516) of the respondents knew that high BP is a possible consequence of high salt intake, while just above one-third, $35.6 \%$ (201) believed it can result in Stroke, and only $5.5 \%$ (31) of respondents did not have knowledge of any possible health consequences. Table 2 showed that more than three-quarters $\{57(87.7 \%)$ and 51 $(78.5 \%)\}$ of all respondents that took salty food a lot, likewise nearly all $\{39(92.9 \%)$ and $38(90.5 \%)\}$ of respondents that added extra salt to food a lot, had high systolic and diastolic BP respectively. This showed that the higher the dietary salt intake, the higher the chances of having poor BP control. The differences between high and normal SBP and DBP respectively for salt intake practices were statistically significant $(\mathrm{p}<0.05)$. 
Table 1: Assessment of Respondents' Knowledge and Practices of Salt Intake

\begin{tabular}{lc}
\hline Variables & $\begin{array}{c}\text { Frequency } \\
\text { n }(\%)\end{array}$ \\
\hline Eating too much salt can affect health & $524(92.9)$ \\
Yes & $18(3.2)$ \\
No & $22(3.9)$ \\
I don't know & \\
Maximum recommended daily salt (teaspoon) & $110(19.5)$ \\
Not more than 1/2 & $226(40.1)$ \\
Not more than 1 & $20(3.6)$ \\
Not more than 1/2 & $95(16.8)$ \\
Not more than 2 & $113(20.0)$ \\
I don't know & \\
Sources of majority of daily salt intake (multiple & \\
responses) & $228(40.4)$ \\
Factory made foods & $454(80.5)$ \\
Salt added to food & $34(6.0)$ \\
I don't know & \\
Salty Food Intake & $65(11.5)$ \\
A lot & $220(39.0)$ \\
Sometimes & $279(49.5)$ \\
Hardly & \\
Addition of Extra salt to food & $42(7.5)$ \\
A lot & $118(20.9)$ \\
Sometimes & $404(71.6)$ \\
\hline Hardly & \\
\hline & \\
\hline
\end{tabular}

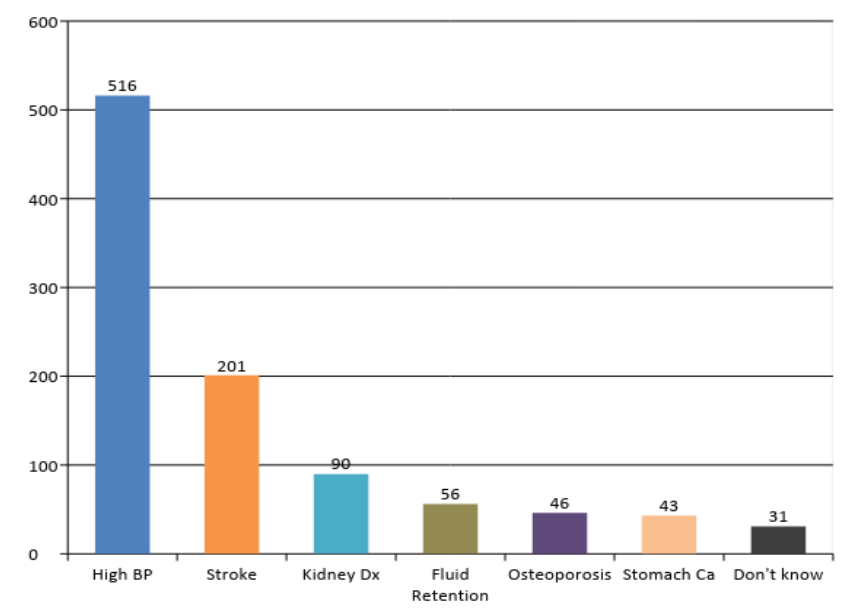

Figure 1: A bar chart showing the perceptions of Respondents on possible health consequences of lots of Salt Intake (multiple responses)
Table 2: Relationship between Salt Intake Practices and Blood Pressure Control among Respondents

\begin{tabular}{|c|c|c|c|c|}
\hline \multirow[t]{2}{*}{ Variables } & \multicolumn{2}{|c|}{ Systolic BP (mmHg) } & \multicolumn{2}{|c|}{ Diastolic BP (mmHg) } \\
\hline & $\begin{array}{l}\text { High }(\geq 140) \\
n=428\end{array}$ & $\begin{array}{l}\begin{array}{l}\text { Normal } \\
(<140)\end{array} \\
\mathbf{n}=136 \\
\end{array}$ & $\begin{array}{l}\text { High }(\geq 90) \\
n=360\end{array}$ & $\begin{array}{l}\text { Normal }(<90 \\
\mathrm{n}=204\end{array}$ \\
\hline \multicolumn{5}{|c|}{ Salty food intake } \\
\hline A lot & $57(87.7)$ & $8(12.3)$ & $51(78.5)$ & $14(21.5)$ \\
\hline Sometimes & $174(79.1)$ & $46(20.9)$ & $156(70.9)$ & $64(29.1)$ \\
\hline Hardly & $197(70.6)$ & $82(29.4)$ & $153(54.8)$ & $126(45.2)$ \\
\hline Statistics & $\chi^{2}=10.431$, & $p=0.005$ & $\chi^{2}=20.572$, & $p<0.001$ \\
\hline \multicolumn{5}{|c|}{ Addition of extra salt to food } \\
\hline A lot & $39(92.9)$ & $3(7.1)$ & $38(90.5)$ & $4(9.5)$ \\
\hline Sometimes & $106(89.8)$ & $12(10.2)$ & $102(86.4)$ & $16(13.6)$ \\
\hline Hardly & $283(70.0)$ & $121(30.0)$ & $220(54.5)$ & $184(45.5)$ \\
\hline Statistics & \multicolumn{2}{|c|}{$p<0.001 *$} & \multicolumn{2}{|c|}{$p<0.001 *$} \\
\hline
\end{tabular}

\section{DISCUSSION}

Studies that have explored knowledge and practices of salt intake and its effects on health in Nigeria and developing nations are scarce. In this study nearly all respondents (92.9\%) knew that eating too much salt can affect health. This is similar to what was reported in America (90\%), but higher than that reported in Australia (62\%). ${ }^{10,14}$ In the same vein, $92.0 \%$ knew that high blood pressure is a possible consequence of excessive salt intake, just as similarly reported among Australian women, ${ }^{14}$. The finding in our study was expected since all respondents were on follow up for hypertension and might have been counselled on the effect of high salt intake and the benefits of low salt diet. The results implied high awareness of salt intake and its consequences.

The present study suggests that most of our respondents did not know the daily recommended level for salt intake. Still majority of them perceived themselves as consuming right amounts of salt. More than one third $(40.1 \%)$ chose $\leq 1$ teaspoon $(2.3 \mathrm{~g}$ of sodium, $6 \mathrm{~g}$ of salt) which was for healthy adults, however only $110(19.5 \%)$ correctly chose $\leq 1 / 2$ teaspoon ( $1.2 \mathrm{~g}$ of sodium, $3 \mathrm{~g}$ of salt) which was for specific groups including hypertensives. The low knowledge found in this study was similar to what was reported by Claro et al and Chalton et al. ${ }^{10,14}$ Patients with hypertension should consume no more than 5 grams of salt a day according to WHO guideline, ${ }^{6,11}$ while 2007 recommendations for healthy adult recommended a maximum intake of salt at 6 gram/day. ${ }^{2}$

In contrast most participants remarked that they had already limited salt intake, which might reflect inappropriate understanding. Remarkably the awareness of salt and sodium 
consumption did not ensure sufficient knowledge. Previous studies in American countries found similar findings. ${ }^{10,15,16}$ In Grimes et al., $73 \%$ of participants were not informed of the maximum allowed amount of salt ${ }^{17}$. Lack of knowledge is one of the other barriers to reduce sodium intake in patients. Information concerning an appropriate understanding of recommended salt intake and the importance of salt reduction program are necessary for successful treatment. In a qualitative study a patient said that "my doctor said that I do not add salt to food, and I have no other information" ${ }^{18,19}$. Merely writing a single line prescription "decrease salt in diet" will not change the food behaviour of the patients, overnight. Changing food behaviour is not an easy task. It takes time and sustained effort. In fact, salt reduction is beneficial in both normotensive and hypertensive people. A review of randomized controlled trials found that reduction of salt $1 \mathrm{~g}$ for at least 6 months' period cause a reduction in systolic and diastolic pressure by $1 \mathrm{mmHg}$ in normotensives and by an average of $2-4 \mathrm{mmHg}$ in hypertensive patients. $^{20-22}$

Just as was reported among Shandong residents ${ }^{2}$, those who were aware of the links between sodium and hypertension were more likely to take action towards sodium reduction.

Our study shows that, excess sodium intake is associated with increased blood pressure. The higher the dietary salt intake, the higher the chances of having poor BP control. The farther away the respondents are to the consumption of salty food, the higher the chances of having normal blood pressure.

\section{CONCLUSION}

Although patients were knowledgeable about the possible health consequences of salt, low rate knew the daily intake recommended value. The lower the dietary salt intake, the higher the chances of having good BP control. Increased knowledge about recommended salt intake and individual guidance could be important for reducing salt intake in hypertensive patients.

\section{LIMITATIONS}

Limitation of this study includes self-reported attitude and practices of participants for having low or high sodium diet, which may overestimate or underestimate their actual attitude and practices related to sodium consumption. As a crosssectional study, the findings could only be used to examine associations and not to draw inferences regarding causality.

\section{Conflicts of interest}

None declared.

\section{REFERENCES}

1. Appel LJ, Angell SY, Cobb LK, Limper HM, Nelson DE, Samet JM, et al. Population-wide sodium reduction: the bumpy road from evidence to policy. Ann Epidemiol. 2012;22: 417-425.

2. Zhang J, Xu A-q, Ma J-x, Shi X-m, Guo X-1, Engelgau M, et al. Dietary Sodium Intake: Knowledge, Attitudes and Practices in Shandong Province, China, 2011. PLoS ONE. 2013; 8(3): e58973. doi:10.1371/journal.pone.0058973

3. Sarmugam R, Worsley A, and Wang W, "An examination of the mediating role of salt knowledge and beliefs on the relationship between socio-demographic factors and discretionary salt use: a cross-sectional study,"The International Journal of Behavioral Nutrition and Physical Activity. 2013; 10:25.

4. Bibbins-Domingo K, Chertow GM, Coxson PG, Moran A, Lightwood JM, Pletcher MJ, et al. Projected effect of dietary salt reductions on future cardiovascular disease. $\mathrm{N}$ Engl J Med. 2010;362(7): 590-599.

5. Beaglehole R, Bonita R, Horton R, Adams C, Alleyne G, Asaria $\mathrm{P}$, et al. Priority actions for the non-communicable disease crisis. Lancet. 2011; 377: 1438-1447.

6. WHO. Guideline: sodium intake for adults and children. Geneva: World Health Organization, 2012. Available at http://www.who.int/nutrition/publications/guidelines/sodiu m_intake/en/.

7. Elliott P, Brown I. Sodium intakes around the world. Geneva: World Health Organization; 2007: 6-15.

8. WHO. A global brief on hypertension: silent killer, global public health crisis. Geneva: World Health Organization; 2016.

9. Cornelio ME, Gallani MCBJ, Godin G, Rodrigues RCM, Mendes RDR, Nadruz JW. Development and reliability of an instrument to measure psychosocial determinants of salt consumption among hypertensive patients. Latin Am J Nurs. 2009;17(5):701-707.

10. Claro RM, Lindersn L, Ricardo CZ, Legetic B, Campbell NRC. Consumer attitudes, knowledge, and behavior related to salt consumption in sentinel countries of the Americas. Rev Panam Salud Publica. 2012;32(4):265-273. 
11. Wicaksana AL. Knowledge, attitude and behavior toward dietary salt: The nescience among hypertensive patients in Indonesia. Int J Res Med Sci. 2017;5:3413-3419.

12. Asekun-Olarinmoye EO, Akinwusi PO, Adebimpe WO, Isawumi MA, Hassan MB, Olowe OA, et al. Prevalence of hypertension in the rural adult population of Osun State, Southwestern Nigeria. Int J Gen Med. 2013;6:317-322.

13. James PA, Oparil S, Carter BL, Cushman WC, DennisonHimmelfarb C, Handler J, et al. 2014 evidence-based guideline for the management of high blood pressure in adults: report from the panel members appointed to the eighth joint national committee (JNC 8). Jama. 2014;311(5):507-520.

14. Charlton K, Yeatman H, Houweling F, Guenon S. Urinary sodium excretion, dietary sources of sodium intake and knowledge and practices around salt use in a group of healthy Australian women. Aust N Z J Public Health. 2010;34(4):356-363.

15. Teixeira JF, Goulart MR, Busnello FM, Pellanda LC. Hypertensive's knowledge about high-sodium food and their behavior. Arq Bras Cardiol. 2016;106:404-410.

16. Papadakis S, Pipe AL, Moroz IA, Reid RD, Blanchard $\mathrm{CM}$, Cote DF, et al. Knowledge, attitudes and behaviours related to dietary sodium among 35-to 50-years-old Ontario residents. Canadian J Cardiol. 2010;26:e164-169.

17. Grimes CA, Riddell LJ, and Nowson CA. Consumer knowledge and attitudes to salt intake and labelled salt information. Appetite.2009;53(2):189-194

18. Sheahan SL and Fields B. Sodiumdietary restriction, knowledge, beliefs, and decision-making behavior of older females. Journal of the American Academy of Nurse Practitioners.2008;20 (4):217-224.

19. Kamran A, Azadbakht L, Sharifirad G, Mahaki B and Sharghi A. Sodium Intake, Dietary Knowledge, and Illness Perceptions of Controlled and Uncontrolled Rural Hypertensive Patients. International Journal of Hypertension.2014;245480;1-7. http://dx.doi.org/10.1155/2014/245480

20. World Health Organization. Reducing Salt Intake in Populations. Report of WHO Forum and Technical Meeting. Paris; 2006.

21. Alderman MH. Reducing dietary sodium: The case for caution. JAMA. 2010;303:448-449.

22. Bhattacharya S, Thakur JS, Singh A. Knowledge attitude, and practice regarding dietary salt intake among urban slum population of North India. J Family Med Prim Care. 2018;7:526-530. 